\title{
Isthmocele: an overview of diagnosis and treatment
}

\author{
Thaysa Guglieri Kremer \\ DIsadora Bueloni Ghiorzi² \\ (D) Raquel Papandreus Dibi ${ }^{3}$
}

\begin{abstract}
1. Department of Medicine at the Federal University of Rio Grande do Sul (UFRGS), Porto Alegre, RS, Brasil 2. Department of Medicine at the Federal University of Health Sciences of Porto Alegre (UFCSPA), Porto Alegre, RS, Brasil 3. Department of Gynecology and Obstetrics at the Federal University of Health Sciences of Porto Alegre (UFCSPA), Porto Alegre, RS, Brasil
\end{abstract}

\section{SUMMARY}

An isthmocele, a cesarean scar defect or uterine niche, is any indentation representing myometrial discontinuity or a triangular anechoic defect in the anterior uterine wall, with the base communicating to the uterine cavity, at the site of a previous cesarean section scar. It can be classified as a small or large defect, depending on the wall thickness of the myometrial deficiency. Although usually asymptomatic, its primary symptom is abnormal or postmenstrual bleeding, and chronic pelvic pain may also occur. Infertility, placenta accrete or praevia, scar dehiscence, uterine rupture, and cesarean scar ectopic pregnancy may also appear as complications of this condition. The risk factors of isthmocele proven to date include retroflexed uterus and multiple cesarean sections. Nevertheless, factors such as a lower position of cesarean section, incomplete closure of the hysterotomy, early adhesions of the uterine wall and a genetic predisposition may also contribute to the development of a niche. As there are no definitive criteria for diagnosing an isthmocele, several imaging methods can be used to assess the integrity of the uterine wall and thus diagnose an isthmocele. However, transvaginal ultrasound and saline infusion sonohysterography emerge as specific, sensitive and cost-effective methods to diagnose isthmocele. The treatment includes clinical or surgical management, depending on the size of the defect, the presence of symptoms, the presence of secondary infertility and plans of childbearing. Surgical management includes minimally invasive approaches with sparing techniques such as hysteroscopic, laparoscopic or transvaginal procedures according to the defect size.

KEYWORDS: cesarean section; hysteroscopy; laparoscopy; uterine bleeding.

\section{INTRODUCTION}

The World Health Organization recommends as ideal a cesarean section (CS) rate of $10-15 \%$ of all births. ${ }^{1}$ However, the percentages of CS delivery in South America (42.9\%), Latin America (40.5\%), North America (32.3\%) and Europe $(25 \%)^{2}$ are well above this number. This has led to a worldwide discussion about the complications and consequences of the procedure, which are also increasing in number. ${ }^{3}$
Some of them, such as scar dehiscence, placenta praevia and accreta are already established and studied. Others, however, are only recently gaining more importance, ${ }^{4}$ which is the case of the cesarean scar defect, isthmocele or niche.

The isthmocele is a myometrial defect resembling a pouch on the anterior wall of the uterine isthmus, over a previous cesarean scar. ${ }^{5,6}$ This defect contrib- 
utes to pathologic changes that may predispose the emergence of symptoms like menorrhagia, ${ }^{7}$ abnormal uterine bleeding (AUB), ${ }^{8}$ pelvic pain, dysmenorrhea, cesarean scar pregnancy and secondary infertility. ${ }^{8,9}$

Guidelines for diagnostic criteria and treatment of isthmocele are still unclear. Currently, the treatment options include conservative treatment based on combined estrogen and progesterone therapy and hysteroscopic, laparoscopic, or transvaginal surgical repair. ${ }^{10}$

The objective of this review is to present an overview of the current literature on isthmocele, approaching its classification, predisposing factors for the niche development, clinical symptoms, diagnostic methods, and the current treatment options, focusing on minimally invasive approaches.

\section{DEFINITION, CLASSIFICATION, AND PREVALENCE}

\section{a. Definition}

There is no universal definition of isthmocele or standard characterization that clearly indicates its location and size. ${ }^{11}$ Several authors have proposed definitions in an attempt of establishing a universal concept. Overall, most studies refer to isthmocele, cesarean scar defect, niche or diverticulum as a myometrial discontinuity or a hypoechoic triangle in the myometrium of the anterior uterine wall at the site of hysterotomy presented in transvaginal ultrasound (TVUS) or sonohysterography (SHG) examination in non-pregnant women. ${ }^{3,4,8,11}$ Other studies, nonetheless, describe the pouch as a myometrial thinning, an anechoic defect $>1 \mathrm{~mm}$ or a defect of the myometrium of $>2 \mathrm{~mm}$ at the place of a cesarean scar. ${ }^{12-14}$ Even so, the defect usually presents abundant and ectatic vessels, covered in smooth mucosa and menstrual blood often fills the pouch. ${ }^{15}$ Gubbini has described that the site of the defect varies according to the site of the $\mathrm{CS}$, which relates to the stage of labor, uterine cervix changes, and the surgical technique. ${ }^{5}$

\section{b. Classification}

Some authors classified the findings according to the size of the defect: ${ }^{4}$ a large defect is described as a myometrial reduction of $>50 \%$ of the wall thickness ${ }^{14}$ or even $>80 \%$ by some authors. ${ }^{4,16}$ A large defect may also be classified as residual myometrium (RM) $<2.2 \mathrm{~mm}$ by TVUS and $<2.5 \mathrm{~mm}$ by SHG. ${ }^{17}$ For management purposes, Marotta et al. ${ }^{18}$ adopted the cutoff of $\mathrm{RM}<3 \mathrm{~mm}$ as a large defect and a $\mathrm{RM} \geq 3 \mathrm{~mm}$ as a small defect. These radiologic findings can be found incidentally in the absence of symptoms or be associated with clinical symptoms. Therefore, they can also be classified as asymptomatic or symptomatic when presenting AUB, pelvic pain, and infertility, for example. $^{8}$

\section{c. Prevalence}

The exact prevalence of isthmocele is unknown and is related to the method used to assess the defect. ${ }^{12}$ In a recent systematic review, Tulandi and Cohen ${ }^{4}$ have found that the prevalence of isthmocele rages from $24 \%$ to $70 \%$ in TVUS examination and from $56 \%$ to $84 \%$ in SHG in women with 1 or more previous CS.,4 When compared with asymptomatic patients, the prevalence is higher in those with symptoms, ranging according to the literature, from $19.4 \%$ to $84 \%,{ }^{13,19}$ with postmenstrual spotting as the main symptom. ${ }^{4,20}$

\section{ETIOPATHOGENESIS AND RISK FACTORS}

Several risk factors have been related to the development of the isthmocele; however, there are few associations proven to date. Ofili-Yebovi et al. ${ }^{14}$ first presented an association between isthmocele and multiple previous CS, retroflexed uterus, and failure to identify all CS scars during repeat CS of multiple $\mathrm{CS}$, later corroborated by several authors. ${ }^{20}$

Tulandi and Cohen $^{4}$ also reviewed predisposing factors recently, stating that even though several risk factors have been linked to isthmocele, multiple CS is the principal risk factor for its development. Although demonstrating inconclusive results, Bij de Vaate et al. ${ }^{3}$ hypothesized in a systematic review that duration of labor, dilatation, stage of the presenting part, and a lower position of the CS hysterotomy may be potential predisposing factors for the development of a niche. A CS conducted in active labor and cervical dilatation $>5 \mathrm{~cm}$ is related to larger isthmoceles.,4 The association of different uterine sutures and the prevalence of isthmocele is still unclear. Although the single-layer myometrial closure appears to increase the risk of isthmocele development when compared to double-layer closure,${ }^{21}$ it is not significantly associated with larger defects. ${ }^{4}$

Concerning the etiology, four hypotheses have been postulated by Vervoort et al. ${ }^{11}$ on causes of isthmocele, depending mostly on surgically induced factors and patient factors. The first hy- 
pothesis concerns the location of the hysterotomy, proposing that a low incision in the cervical part of the uterus is made through cervical tissue, which contains mucous glands, and the mucus produced during the healing could dilate the sutured rims of the myometrium. ${ }^{11}$ This theory is corroborated by several studies that have associated a higher prevalence of isthmocele and patients with cervical dilatation $>5 \mathrm{~cm}$, longer duration of labor $(>5 \mathrm{~h})$ or lower station., ${ }^{3,6,16,22}$ In addition, a high prevalence of isthmocele and CS performed in active labor suggests that an incision made through cervical tissue due to an effaced cervix is more difficult to distinguish from the uterine wall. ${ }^{11,23,24}$

The second hypothesis is related to surgical technique, concerning an incomplete closure of the uterine wall. ${ }^{11}$ The improper closure, or even no closure, of the deeper muscular layer, usually unintentional or related to non-perpendicular sutures and endometrial saving techniques, may lead to an irregular myometrium closure, thus causing the development of isthmocele. ${ }^{11,23}$

The third hypothesis relates to early adhesion development in the hysterotomy scar and the anterior abdominal wall, pulling the edges of the wound and impairing the healing due to those counteracting forces on the uterine scar. ${ }^{11,23}$ This mechanism is even more exuberant in a retroflexed uterus, in which those counteracting forces are increased, potentially decreasing blood flow to the healing tissues. ${ }^{23,24}$

The final hypothesis involves patient factors, suggesting the presence of an individual/genetic predisposition contributing to an impaired wound healing, poor hemostasis, inflammation or adhesion formation, which may influence isthmocele development. ${ }^{11}$

\section{CLINICAL SYMPTOMS}

In general, most isthmoceles are asymptomatic, being found incidentally on ultrasound. ${ }^{23}$ However, over the last decades, with the rising rates of CS, there has been an increase of sequelae reported after this procedure. Symptoms including abnormal uterine bleeding, postmenstrual spotting, dysmenorrhea, pelvic pain, and infertility ${ }^{12,13,20}$ have now been associated with isthmocele. Obstetric complications of isthmocele were described in the literature, such as placenta accrete, placenta praevia, scar dehiscence, uterine rupture, and ectopic pregnancy in cesarean scar defects. ${ }^{8,24}$

\section{Gynecologic Complications}

Abnormal uterine bleeding (AUB), mostly characterized as postmenstrual bleeding, is the main symptom related to the presence of an isthmocele, being present in $28.9 \%$ to $82 \%^{12,13,22,25}$ women with isthmocele. $^{4}$

The presence of isthmocele may predispose a deposit of blood and menstrual debris within the defect, associated to reduced contractility of the uterus due to fibrotic tissue around the scar, slowing the drainage of the menstrual flow and causing AUB. ${ }^{13,26}$ Pathology findings of free erythrocytes in the scar tissue suggesting a recent hemorrhage lead Morris ${ }^{7}$ to propose that the blood could also be produced in situ, also causing intermittent spotting. Regardless of the source, the presence of blood in the isthmocele is also associated with a higher mucus secretion, which could contribute to postmenstrual AUB. ${ }^{6}$

Also, an association between the isthmocele size and postmenstrual bleeding has been established. ${ }^{20}$ Postmenstrual spotting is more frequent in patients with larger defects than in patients with smaller defects. $^{12}$

Dysmenorrhea and pelvic pain have also been described in isthmocele in studies over the last decade. Wang et al. $^{20}$ stated a correlation concerning the isthmocele size and pelvic pain and dysmenorrhea. Morris ${ }^{7}$ suggested that those pain complaints were related to inflammatory infiltration, fibrosis and anatomic disruption of the lower uterine segment.

Although these symptoms of AUB, dysmenorrhea and pelvic pain are a common complaint in the gynecological office, isthmocele has grown as a differential diagnosis in women who underwent a CS. ${ }^{8}$ Tulandi and Cohen ${ }^{4}$ found an increase from $63.8 \%$ to $82 \%$ in the rate of isthmocele in women presenting postmenstrual bleeding who underwent TVUS or SHG due to gynecologic symptoms. Therefore, if a patient with previous CS presents any of the symptoms such as above, symptomatic isthmocele should be part of the differential diagnosis and thus investigated. ${ }^{23}$

The association between isthmocele and secondary infertility has been reported in the literature with a high prevalence. ${ }^{6,8}$ The presence of blood in the isthmocele could affect the cervical mucus and sperm quality, obstruct sperm transport and make embryo implantation more difficult, therefore impairing fertility. ${ }^{27,28}$ Several studies have evaluated the fertility outcomes after isthmocele treatment, ${ }^{28}$ 
demonstrating that the repair of the defect is associated with high rates of restoring fertility. ${ }^{6}$

\section{Obstetric Complications}

The presence of an isthmocele is associated with an increased risk of complications during pregnancy, including placenta previa, accrete/increta/percreta, scar dehiscence, uterine rupture, and cesarean scar ectopic pregnancy. ${ }^{24}$ The risk of an isthmocele becoming deficient is related to multiple CS. ${ }^{14,17}$ The overall rate of uterine rupture during a posterior pregnancy does not exceed $2 \%$, however, in larger defects, this risk increases to $5 \% .{ }^{24}$ It appears that scar thickness in ultrasonographic assessment has no practical use as a prognostic marker of uterine rupture..$^{14,24}$

One of the rarest obstetric complications, the cesarean scar ectopic pregnancy, occurs when the embryo is implanted in the myometrium of the cesarean scar defect. Over the last decades, there has been a rise in the prevalence of the cesarean scar ectopic pregnancy, as well as the CS and therefore isthmocele rates. $^{29}$

\section{DIAGNOSIS}

There are no definitive criteria for the diagnostic of isthmocele. ${ }^{4,8,19}$ Various imaging methods including ultrasonography, sonohysterography, hysterography, hysteroscopy, and magnetic resonance imaging can be used to assess the anterior uterine wall and diagnose isthmocele. ${ }^{18}$

Transvaginal ultrasound (TVUS) is the initial and most usual method described to assess the integrity of the uterus wall in non-pregnant patients. ${ }^{8,18}$ Because the principal symptom is postmenstrual bleeding, the early proliferative phase best shows the deposit of blood within the isthmocele, allowing its identification even without the necessity of saline or gel infusion ${ }^{4}$ and there is minimal chance of pregnancy. ${ }^{23,30}$ The defect has been described on TVUS as an anechoic triangle defect in the myometrium with the base communicating to the uterine cavity, or a deformity (wedge, shape, concavity or sacculation) on the anterior isthmus. ${ }^{22,31}$

The prevalence of isthmocele in sonohysterography (SHG), when compared with TVUS, appears to be higher (56\%-84\% against $24 \%-70 \%$ ). Nevertheless, SHG is more sensitive than TVUS, , ,12,13,16,17,32 and the defect seems larger or deeper by SHG. ${ }^{12}$ Therefore, the saline infusion sonohysterography (SIS) is more sensitive and specific for the identification of isthmocele $^{26}$ by filling the defect and providing contrast. ${ }^{8}$ When compared to the TVUS, SIS presented better results by detecting more defects and more often classifying them as larger on average of 1 to $2 \mathrm{~mm} \cdot{ }^{32}$ Gel instillation sonography (GIS) also presents a higher prevalence in detecting the defect when compared to TVUS (49.6\% against $64.5 \%) .^{12}$ Furthermore, similarly to SIS, the defect shown on GIS was larger and the RM smaller comparing to TVUS only. ${ }^{12}$ This effect on prevalence and defect size diagnosed by SHG is a consequence of a pressure increase inside the uterus, which causes an enhancing on the defect size. $^{4}$

Hysterography (HSG) can also assess the isthmocele; however, it cannot measure the myometrial thickness, which is a limitation of this method. Moreover, if blood or mucus is accumulated in the isthmocele, HSG may not clearly identify the defect. ${ }^{23}$

Using magnetic resonance imaging (MRI) allows determining the RM thickness of the isthmocele on the sagittal T2-weighted views. Nevertheless, Marotta et al. ${ }^{18}$ found that RM measurements in MRI were related to those assesses through TVUS.

Hysteroscopy enables direct visualization and confirmation of the isthmocele..$^{19,22}$ Usually described as a pouch or a discontinuity of the anterior uterine wall, ${ }^{6,22}$ hysteroscopy allows for visualization and potential treatment; however, it may not assess de RM thickness.

TVUS and SHG can both be performed in the office, are more affordable than MRI, less invasive than hysteroscopy and produce reliable measurements. ${ }^{23}$ If an isthmocele is suspected, several authors ${ }^{6,8,23}$ recommend SIS as a diagnostic study based on its greater sensitivity and specificity for planning surgery and research purposes.

\section{Treatment}

The treatment of isthmocele ranges from clinical management with expectant or pharmacological treatment, surgical treatment, and hysterectomy to sparing techniques including hysteroscopic, laparoscopic, laparotomic, or transvaginal procedures limited to the defect site. ${ }^{9}$ The decision to treat takes into consideration the size of the defect, presence of symptoms, secondary infertility and plans of pregnancy. ${ }^{8,19,23}$

In the case of incidental diagnosis of asymptomatic isthmocele and no plans for future childbearing, clinical observation and no surgical intervention are 
usually recommended..$^{18,23}$ In symptomatic women with either AUB, pelvic pain, or secondary infertility, the course of treatment depends upon the size of their defect. There are a great number of studies proposing different surgical approaches and techniques to the correction of the cesarean scar defect. ${ }^{9,18,23,33,34}$

\section{Clinical Management}

Expectant treatment is an option for women with small isthmoceles $(\mathrm{RM} \geq 3 \mathrm{~mm}){ }^{18}$ However, in a recent study, Vervoort et al. ${ }^{35}$ randomized symptomatic women with small defects $\geq 3 \mathrm{~mm}$ into expectant treatment or hysteroscopic resection, achieving a decrease in the number of postmenstrual spotting and spotting-related discomfort in women submitted to the procedure.

Clinical management has been described to have failed to reduce symptoms in most of the subjects treated with oral contraceptives, as observed by Thurmond et al. ${ }^{26}$. However, Tahara et al. ${ }^{36}$ presented a preliminary report with positive results in eliminating intermenstrual bleeding after three cycles of oral contraceptives in relatively higher doses. Despite the contrasting results, the current data present as the first choice of treatment for symptomatic isthmocele the resection of the defect due to its minimally invasive approach and good therapeutic results. ${ }^{5,15,19,37}$

\section{Hysteroscopy}

Hysteroscopic resection of isthmocele is a minimally invasive, non-time-consuming and low morbidity procedure, allowing visualization and repair of the defect. ${ }^{9}$ Despite the great variety of technique among the authors, the surgical technique overall consists of the resection of fibrotic tissue from the defect, presented like a flap underneath the triangular pouch. The resection of the niche edges setting the wall in continuity to the cervical canal improves the flow drainage and prevent the retention of menstrual blood. ${ }^{6,9}$ Fulguration of the base of the pouch, either globally or targeting visible vessels, enables the removal of the inflamed and congested tissue, preventing the in situ production of fluid and blood..$^{8}$ In a systematic review, Abacjew-Chmylko et al. ${ }^{9}$ presented favorable outcome rates of hysteroscopic resection of $85.5 \%$, ranging from $59.6 \%$ to $100 \%$, completely solving AUB symptoms in $72.4 \%$ of the cases. Uterine perforation and bladder injuries are the major risks of the hysteroscopic procedure. Therefore, in order to reduce this risk, the resectoscope treatment by hysteroscopy is recommended to be performed if the remaining myometrial thickness is $>3 \mathrm{~mm} .{ }^{18}$

\section{Laparoscopy}

A laparoscopic approach has been advocated for large defects $(\mathrm{RM}<3 \mathrm{~mm})$, in the presence of symptoms and desire to maintain fertility. ${ }^{18}$ Laparoscopic isthmocele repair consists in the resection of the isthmocele edges, in order to excise the scar tissue, closing the defect in two-layer sutures. ${ }^{4}$ Laparoscopy enables a better visualization to identify the defect, allowing repair and thus increasing the myometrial thickness. ${ }^{23}$

Donnez et al. ${ }^{33}$ described large isthmocele (RM $<3 \mathrm{~mm}$ ) laparoscopic repair outcomes in thirty-eight symptomatic women. The surgical technique used was laparoscopic excision of the isthmocele with $\mathrm{CO} 2$ laser. A Hegar probe was used after the excision of the defect to preserve uterine continuity through the canal. The excision was repaired in three layers, the first two closed with separated Vicryl sutures, and the peritoneum closed with Monocryl in a running suture. In the case of a retroflexed uterus, a shortening of the round ligaments was done to decrease the counteracting forces that may impair the wound healing, as suggested by Vervoort et al. ${ }^{11}$ Hysteroscopy was then conducted to assert the repair. The mean myometrial thickness raised from $1.43 \pm 0.7$ to $9.62 \pm 1.8 \mathrm{~mm}$ in 3-month follow-ups. A total of $93 \%$ of the patients were symptom-free, and among women with infertility, $44 \%$ achieved pregnancy and delivered healthy full-term babies. ${ }^{33}$ The significant increase in myometrial thickness demonstrated the effectiveness that a laparoscopic isthmocele repair has on restoring the anterior uterine wall integrity. ${ }^{23}$

Vervoort et al. ${ }^{37}$ recently published a large prospective study with 101 women with symptomatic isthmocele $<3 \mathrm{~mm}$ submitted to laparoscopic repair under hysteroscopic control. The defect was resected by monopolar hook and the fibrotic tissue excised with a cold scissor, guided by hysteroscopy. The defect was then closed in two-layered suture in full-thickness including endometrium. Hyaluronic acid adhesion barrier was then added. In cases with an extreme retroflexed uterus, the round ligaments were also shortened. Hysteroscopy was performed to evaluate the anatomic result repair. In this study, 80 women had symptoms improved or resolved, and the RM significantly increased in follow up. Of the women with presence of fluid in the uterine cavity, 
this was solved in $86.9 \%$ after the repair, and, in the overall, $83.3 \%$ of women were (very) satisfied with the results. ${ }^{37}$

The combined use of hysteroscopy and laparoscopy offers many advantages. During the laparoscopy, the bladder can be mobilized to offer superior visualization of the isthmocele and thus minimize the risk of bladder injury. Moreover, the cavity can be assessed for diagnosis and possible immediate surgical treatment of other conditions that can cause pain or infertility, such as chronic pelvic inflammatory disease or endometriosis. The hysteroscopy light source transilluminates the pouch providing guidance in identifying the defect by laparoscopy, and the hysteroscopy can also confirm the laparoscopic repair afterward.$^{10}$

\section{Vaginal Procedure}

The vaginal procedure to isthmocele repair, although minimally invasive and effective, has fewer reports in the literature. ${ }^{38,39}$ Zhang $^{40}$ compared the transvaginal repair to the laparoscopic approach in a retrospective study finding similar outcomes between the two techniques. This technique is described as a dissection of the bladder from the cervix and uterus, opening the vesicovaginal space with the identification of the isthmocele. The defect is excised, and the hysterotomy is closed in two layers. The transvaginal isthmocele repair was found to be cost-effective with shorter operation time and comparably more effective than laparoscopy. ${ }^{40}$ This approach, however, demands the surgeon be greatly experienced in vaginal surgery in order to avoid damage to adjacent structures and accurately locate the isthmocele in the limited surgical view. ${ }^{30,38}$

\section{Hysterectomy}

Hysterectomy is the curative management for large symptomatic isthmocele in women who do not wish to conceive anymore. ${ }^{18}$ Yet, hysterectomy is a major procedure when compared to other minimally invasive approaches available.

\section{ISTHMOCELE AND PREGNANCY}

The assessment of the RM in the lower uterine segment (LUS) by ultrasound can be used to predict the occurrence of cesarean scar dehiscence or rupture in future or ongoing pregnancies. ${ }^{41,42}$ Although several studies have classified LUS in values of high- er or lower risk of scar dehiscence, no cutoff value has been universally defined. A meta-analysis of 2013 presented LUS thickness of 3.1-5.1mm and RM of $2.1-4.0 \mathrm{~mm}$ as a strong negative predictive value for the occurrence of dehiscence or uterine rupture during a trial of labor, and RM of 0.6-2.0 provided a strong positive predictive value for the occurrence of a defect. ${ }^{43}$

Therefore, until newer studies can determine precise values and their implications the clinical practice, the antenatal evaluation of the LUS can be used, as a complementary data alongside other clinical variables, such as number of previous CSs, time between pregnancies, previous vaginal delivery, maternal age, among others, in the decision of a trial of labor after CS or performing a repeat $\mathrm{CS} .{ }^{44}$ However, when performed in nonpregnant women who wish future pregnancies, the RM assessment allows the possibility to identify the defects at higher risk, enabling the possibility of correcting the defect before the next pregnancy. ${ }^{41}$

\section{STRENGTHS AND LIMITATIONS}

The relevance of this study lies, above all, on the high and increasing incidence of isthmocele and its complications. We were able to summarize most aspects regarding this condition, reaching epidemiology, etiopathogenesis, methods of diagnosis and methods of treatment.

However, there was some divergence on the information we found. There is no consensus about the definition of isthmocele, its classification, and prevalence. There are also only hypotheses. Thus, nothing has been proven, to date, about its etiology. Moreover, there are different surgical approaches and techniques recommended in each study.

Therefore, our article contemplates the most important concepts about isthmocele and summarizes the different information we found in the multiple up-to-date studies reviewed.

\section{CONCLUSION}

The increasing prevalence of isthmocele, thus its gynecological and obstetric complications, led by the rising number of CS deliveries performed worldwide is alarming. Postmenstrual spotting, pelvic pain, and secondary infertility are common complaints in gynecologist practice, and isthmocele 
should figure as a differential diagnosis in women with previous CS deliveries, especially in those with risk factors of multiple previous CSs and retroflexed uterus. Diagnosis of isthmocele by TVUS and especially by SIS are cost-effective and have good specificity and sensitivity. Treatment should be offered according to the presence of symptoms, secondary infertility, defect size, and plans for childbearing. The defect can be minimally invasively repaired with sparing techniques by hysteroscopy for small defects, and by vaginal approach, laparoscopy, and combined laparoscopy and hysteroscopy for larger defects.

\section{Financial support \\ The authors declare no financial support.}

\section{Conflict of interest}

The authors declare no conflicts of interest and nothing to disclose.

\section{RESUMO}

A istmocele ou nicho uterino é representada por uma descontinuidade miometrial ou um defeito anecoico triangular na parede uterina anterior, com a base se comunicando com a cavidade uterina no local de uma cicatriz anterior de cesárea. O defeito pode ser classificado como pequeno ou grande, dependendo da espessura da parede miometrial deficiente. Embora geralmente assintomático, seu principal sintoma é o sangramento uterino anormal ou pós-menstrual; a dor pélvica crônica também pode ocorrer. Infertilidade, placenta acreta ou prévia, deiscência de cicatriz, ruptura uterina e gravidez ectópica em cicatriz de cesárea prévia também podem aparecer como complicações dessa condição. Os fatores de risco para desenvolvimento da istmocele comprovados até o momento incluem útero retroverso e múltiplas cesarianas. No entanto, fatores como localização mais inferior de uma cesárea prévia, fechamento incompleto da histerotomia, aderências precoces na parede uterina e predisposição genética também podem contribuir para o desenvolvimento de um nicho. Como não existem critérios definitivos para o diagnóstico de uma istmocele, vários métodos de imagem podem ser usados para avaliar a integridade da parede uterina e, assim, diagnosticar uma istmocele. Entretanto, ultrassonografia transvaginal e sono-histerografia com infusão salina surgem como métodos específicos, sensíveis e custo-efetivos para o diagnóstico de istmocele. O tratamento inclui manejo clínico ou cirúrgico, dependendo do tamanho do defeito, da presença de sintomas, da presença de infertilidade secundária e de planos de gravidez. O manejo cirúrgico inclui abordagens minimamente invasivas como histeroscopia, laparoscopia ou transvaginal, de acordo com o tamanho do defeito.

PALAVRAS-CHAVE: Cesárea. Histeroscopia. Laparoscopia. Sangramento uterino.

\section{REFERENCES}

1. World Health Organization Human Reproduction Programme, 10 April 2015. WHO statement on caesarean section rates. Reprod Health Matters. 2015;23(45):149-50.

2. Betrán $A P$, Ye J, Moller AB, Zhang |, Gülmezoglu AM, Torloni MR. The increasing trend in caesarean section rates: global, regional and national estimates: 1990-2014. PLoS One. 2016;11(2):e0148343.

3. Bij de Vaate AJ, Van der Voet LF, Naji O, Witmer M, Veersema S, Brölmann $\mathrm{HA}$, et al. Prevalence, potential risk factors for development and symptoms related to the presence of uterine niches following cesarean section: systematic review. Ultrasound Obstet Gynecol. 2014;43(4):372-82.

4. Tulandi $T$, Cohen A. Emerging manifestations of cesarean scar defect in reproductive-aged women. J Minim Invasive Gynecol. 2016;23(6):893-902.

5. Gubbini G, Casadio P, Marra E. Resectoscopic correction of the "isthmocele" in women with postmenstrual abnormal uterine bleeding and secondary infertility. J Minim Invasive Gynecol. 2008;15(2):172-5.

6. Florio P, Filippeschi M, Moncini I, Marra E, Franchini M, Gubbini G. Hysteroscopic treatment of the cesarean-induced isthmocele in restoring infertility. Curr Opin Obstet Gynecol. 2012;24(3):180-6.

7. Morris $\mathrm{H}$. Surgical pathology of the lower uterine segment caesarean section scar: is the scar a source of clinical symptoms? Int | Gynecol Pathol. 1995;14(1):16-20

8. Tower AM, Frishman GN. Cesarean scar defects: an underrecognized cause of abnormal uterine bleeding and other gynecologic complications. | Minim Invasive Gynecol. 2013;20(5):562-72

9. Abacjew-Chmylko A, Wydra DG, Olszewska H. Hysteroscopy in the treatment of uterine cesarean section scar diverticulum: a systematic review. Adv Med Sci. 2017;62(2):230-9.
10. Li C, Tang S, Gao X, Lin W, Han D, Zhai J, et al. Efficacy of combined laparoscopic and hysteroscopic repair of post-cesarean section uterine diverticulum: a retrospective analysis. Biomed Res Int. 2016;2016:1765624.

11. Vervoort AI, Uittenbogaard LB, Hehenkamp WI, Brölmann HA, Mol BW, Huirne JA. Why do niches develop in Caesarean uterine scars? Hypotheses on the aetiology of niche development. Hum Reprod. 2015;30(12):2695-702.

12. Van der Voet LF, Bij de Vaate AM, Veersema S, Brölmann HA, Huirne JA. Long-term complications of caesarean section. The niche in the scar: a prospective cohort study on niche prevalence and its relation to abnormal uterine bleeding. BJOG. 2014;121(2):236-44

13. Bij de Vaate AJ, Brölmann HA, van der Voet LF, van der Slikke JW, Veersema S, Huirne |A. Ultrasound evaluation of the cesarean scar: relation between a niche and postmenstrual spotting. Ultrasound Obstet Gynecol. 2011;37(1):93-9

14. Ofili-Yebovi D, Ben-Nagi J, Sawyer E, Yazbek J, Lee C, Gonzalez J, et al. Deficient lower-segment cesarean section scars: prevalence and risk factors. Ultrasound Obstet Gynecol. 2008;31(1):72-7.

15. Florio P, Gubbini G, Marra E, Dores D, Nascetti D, Bruni L, et al. A retrospective case-control study comparing hysteroscopic resection versus hormonal modulation in treating menstrual disorders due to isthmocele. Gynecol Endocrinol. 2011;27(6):434-8.

16. Regnard C, Nosbusch M, Fellmans C, Benali N, van Rysselberghe M, Barlow $P$, et al. Cesarean section scar evaluation by saline contrast sonohysterography. Ultrasound Obstet Gynecol. 2004;23(3):289-92.

17. Osser OV, Jokubkiene L, Valentin L. High prevalence of defects in cesarean section scars at transvaginal ultrasound examination. Ultrasound Obstet Gynecol. 2009;34(1):90-7. 
18. Marotta ML, Donnez |, Squifflet |, Jadoul P, Darii N, Donnez O. Laparoscopic repair of post-cesarean section uterine scar defects diagnosed in nonpregnant women. J Minim Invasive Gynecol. 2013;20(3):386-91.

19. Raimondo G, Grifone G, Raimondo D, Seracchioli R, Scambia G, Masciullo $V$. Hysteroscopic treatment of symptomatic cesarean-induced isthmocele: a prospective study. J Minim Invasive Gynecol. 2015;22(2):297-301.

20. Wang CB, Chiu WW, Lee CY, Sun YL, Lin YH, Tseng CJ. Cesarean scar defect: correlation between cesarean section number, defect size, clinical symptoms and uterine position. Ultrasound Obstet Gynecol. 2009;34(1):85-9.

21. Hayakawa H, Itakura A, Mitsui T, Okada M, Suzuki M, Tamakoshi K, et al. Methods for myometrium closure and other factors impacting effects on cesarean section scars of the uterine segment detected by the ultrasonography. Acta Obstet Gynecol Scand. 2006;85(4):429-34.

22. Fabres C, Aviles G, De La Jara C, Escalona J, Muñoz JF, Mackenna A, et al. The cesarean delivery scar pouch: clinical implications and diagnostic correlation between transvaginal sonography and hysteroscopy. J Ultrasound Med. 2003;22(7):695-700.

23. Sipahi S, Sasaki K, Miller CE. The minimally invasive approach to the symptomatic isthmocele - what does the literature say? A step-by-step primer on laparoscopic isthmocele - excision and repair. Curr Opin Obstet Gynecol. 2017;29(4):257-65.

24. Futyma K, Gałczyński K, Romanek K, Filipczak A, Rechberger T. When and how should we treat cesarean scar defect - isthmocoele? Ginekol Pol. 2016;87(9):664-8.

25. Monteagudo A, Carreno C, Timor-Tritsch IE. Saline Infusion sonohysterography in nonpregnant women with previous cesarean delivery: the "niche" in the scar. J Ultrasound Med. 2001;20(10):1105-15.

26. Thurmond AS, Harvey WI, Smith SA. Cesarean section scar as a cause of abnormal vaginal bleeding: diagnosis by sonohysterography. J Ultrasound Med. 1999;18(1):13-6.

27. Fabres $C$, Arriagada $P$, Fernández $C$, MacKenna A, Zegers F, Fernández E. Surgical treatment and follow-up of women with intermenstrual bleeding due to cesarean section scar defect. J Minim Invasive Gynecol. 2005;12(1):25-8

28. Gubbini G, Centini G, Nascetti D, Marra E, Moncini I, Bruni L, et al. Surgical hysteroscopic treatment of cesarean-induced isthmocele in restoring fertility: prospective study. J Minim Invasive Gynecol. 2011;18(2):234-7.

29. Ash A, Smith A, Maxwell D. Caesarean scar pregnancy. BJOG. 2007;114(3):253-63.

30. Liu SJ, Lv W, Li W. Laparoscopic repair with hysteroscopy of cesarean scar diverticulum. J Obstet Gynaecol Res. 2016;42(12):1719-23.

31. Roberge S, Boutin A, Chaillet N, Moore L, Jastrow N, Demers S, et al. Systematic review of cesarean scar assessment in the nonpregnant state: imaging techniques and uterine scar defect. Am J Perinatol. 2012;29(6):465-71.
32. Osser OV, Jokubkiene L, Valentin L. Cesarean section scar defects: agreement between transvaginal sonographic findings with and without saline contrast enhancement. Ultrasound Obstet Gynecol. 2010;35(1):75-83.

33. Donnez O, Donnez J, Orellana R, Dolmans MM. Gynecological and obstetrical outcomes after laparoscopic repair of a cesarean scar defect in a series of 38 women. Fertil Steril. 2017;107(1):289-96.

34. Vervoort AJ, Van der Voet LF, Witmer M, Thurkow AL, Radder CM, van Kesteren PI, et al. The HysNiche trial: hysteroscopic resection of uterine caesarean scar defect (niche) in patients with abnormal bleeding, a randomised controlled trial. BMC Women's Health. 2015;15:103.

35. Vervoort A, van der Voet LF, Hehenkamp W, Thurkow AL, van Kesteren $P$, Quartero $H$, et al. Hysteroscopic resection of a uterine caesarean scar defect (niche) in women with postmenstrual spotting: a randomised controlled trial. BJOG. 2018;125(3):326-34.

36. Tahara M, Shimizu T, Shimoura H. Preliminary report of treatment with oral contraceptive pills for intermenstrual vaginal bleeding secondary to a cesarean section scar. Fertil Steril. 2006;86(2):477-9.

37. Vervoort A, Vissers |, Hehenkamp W, Brölmann H, Huirne |. The effect of laparoscopic resection of large niches in the uterine caesarean scar on symptoms, ultrasound findings and quality of life: a prospective cohort study. BJOG. 2018;125(3):317-25.

38. Luo L, Niu G, Wang Q, Xie HZ, Yao SZ. Vaginal repair of cesarean section scar diverticula. J Minim Invasive Gynecol. 2012;19(4):454-8.

39. Chen $Y$, Chang $Y$, Yao $S$. Transvaginal management of cesarean scar section diverticulum: a novel surgical treatment. Med Sci Monit. 2014;20:1395-9.

40. Zhang Y. A comparative study of transvaginal repair and laparoscopic repair in the management of patients with previous cesarean scar defect. J Minim Invasive Gynecol. 2016;23(4):535-41.

41. Pomorski M, Fuchs T, Zimmer M. Prediction of uterine dehiscence using ultrasonographic parameters of cesarean section scar in the nonpregnant uterus: a prospective observational study. BMC Pregnancy and Childbirth. 2014;14:365.

42. Qureshi B, Inafuku I, Oshima K, Masamoto H, Kanazawa K. Ultrasonographic evaluation of lower uterine segment to predict the integrity and quality of cesarean scar during pregnancy: a prospective study. Tohoku J Exp Med. 1997;183(1):55-65.

43. Kok N, Wiersma IC, Opmeer BC, Graaf IM, Mol BW, Pajkrt E. Sonographic measurement of lower uterine segment thickness to predict uterine rupture during a trial of labor in women with previous Cesarean section: a meta-analysis. Ultrasound Obstet Gynecol. 2013;42(2):132-9.

44. Jastrow N, Vikhareva O, Gauthier RJ, Irion O, Boulvain M, Bujold E. Can third-trimester assessment of uterine scar in women with prior $\mathrm{Ce}-$ sarean section predict uterine rupture? Ultrasound Obstet Gynecol. 2016;47(4):410-4. 